Kalpa Publications in Engineering
Volume 1, 2017, Pages 187-192
ICRISET2017. International Conference on Re-
search and Innovations in Science, Engineering
\&Technology. Selected Papers in Engineering

\title{
An Overview on Problem of Balancing Of DC Capacitor Voltage in Diode-Clamped Multilevel Inverter Using Boost Converter
}

\author{
Shubham R Patel ${ }^{1}$,Gaurang K Sharma ${ }^{2}$ and Ashish R Patel ${ }^{3}$ \\ ${ }^{1}$ M. tech Electrical Engineering, ${ }^{2,3}$ Assistant Professor Electrical Engineering \\ ${ }^{1,2,3}$ B.V.M Engineering College, Vallabh Vidyanagar, INDIA \\ shubhampatel2206@gmail.com, \\ gksharma@bvmengineering.ac.in, ashish.patel@bvmengineering.ac.in
}

\begin{abstract}
Multilevel inverter allows the production of high voltage with lower harmonic distortion in ac output and it eliminates the need of transformer. With the usage of multilevel inverter, we can get the required ac voltage output from multiple dc voltage rails. One of the disadvantage in it is the unbalancing of dc link capacitor voltage. The basic aim of this paper is the balancing of dc link capacitor voltage in diode-clamped multilevel inverter. There are different approaches which could be used for balancing of the capacitor voltage. In this paper, the method of additional auxiliary circuit in the form of Two-level Boost converter is being adopted to balance the inner capacitor voltages so as to get the required multilevel output. This balancing leads to the reliability in the inverter output voltage and extension in life of capacitor. The simulations for this are being performed in MATLAB SIMULINK $^{\circledR}$ and the result are being analyzed for the same by employing it for different load condition. The scheme thus offer the proper balancing of capacitor voltage.
\end{abstract}

\section{Keywords}

DC link Capacitor voltage balancing; diode-clamped multilevel inverter; LC filter; Two-level boost converter

\section{Introduction}

There are basically three types of highly popular voltage source multilevel inverters. They are being categorized based on their network topologies as diode-clamped multilevel inverter or neutral point clamped inverter, flying capacitor multilevel inverter and cascaded or H-Bridge inverter [1]. 
This different multilevel inverter could be used in applications like static VAR compensators, variable speed motor drives, high voltage grid interconnection. From the studies carried out earlier it has been found that the method of using passive front end capacitor voltage balancing is only possible if the modulation index is limited to $60 \%$ of the inverter load and 0.8 power factor.

This limitation could be overcome by using different techniques such as inverter being supplied by isolated dc sources, using of the balancing circuit that transfers the the additional charge acquired to the uncharged capacitor or the modification of pulse width modulation switching pattern [2].

To avoid the extra cost involved in the additional balancing circuit many authors suggested in modifying the switching pattern,but this method had several of the limitation.PWM strategy once employed alone could not cope up with the problems like total harmonic distortation,Common mode voltage cancellation and leakage current.To avoid this limitation a modified boost converter in the form of Two Level boost converter[TLBC] is being employed.It is advantageous in high voltage applications because of reduced switching losses and reduced recovery losses and the requirement of lower inductor size for providing the additional voltage.Also the current ripple is halved compared to conventional boost converter [3][4].Therefore in this paper de voltage balancing of inner capacitor is performed using two level boost converter.

\section{Diode clamped multilevel inverter}

Three level neutral point clamped converter was proposed by Nabae et.al in 1981.In a total there were two capacitors connected in series to form an additional level. It is being named as neutral point clamped inverter because the additional level of this was the neutral point of the dc bus. Diodeclamped multilevel inverter/neutral point clamped inverter is one of the most conventional topology in multilevel inverters where diode is being used to clamp the dc output voltage to obtain the desired output. A single-phase inverter consists of (m-1) dc link capacitors,2(m-1) switching devices and (m1) $(\mathrm{m}-2)$ clamping diodes [1]. This is shown in fig 1 .

To get the desired output voltage the switches as shown in fig. 1 are turned on accordingly as follows [1]

Here the upper switches are referred to as $\mathrm{S}_{1}-\mathrm{S}_{4}$ and lower switches as $\mathrm{S}_{1}{ }^{\prime}-\mathrm{S}_{4}{ }^{\prime}$.

1.For voltage level $=\mathrm{Vdc} / 2$ all upper switches are turned on.

2.For voltage level $=\mathrm{Vdc} / 4$ three upper and one lower switch is turned on.

3.For Voltage level $=0$ two upper and two lower switches are turned on.

4.For voltage level $=-\mathrm{Vdc} / 4$ one upper and three lower switches are turned on

5.For voltage level $=-\mathrm{Vdc} / 2$ all lower switches are turned on.

Disadvantage/limitation observed in diode clamped multilevel inverter is the need of additional clamping diodes and de link capacitor voltage unbalancing.

The total dc voltage is being equally distributed across the de link of the capacitor but due to the different duration working of the capacitors some of the capacitors used up are more frequent than the other. As shown in fig.2 during a particular interval both capacitors $\mathrm{C}_{1}$ and $\mathrm{C}_{2}$ are used. During this time both the capacitors discharges. But after some interval of time again the capacitor $\mathrm{C}_{2}$ is being used up to supply the load so it keeps on discharging. So, if this voltage is not being balanced it further leads to the condition where the inner capacitors voltage is nearly zero due to this the multilevel inverter start behaving as a simple three level inverter.This voltage unbalancing exists regardless of different load condition [1] for this a strategy of voltage balancing of dc link capacitor. 


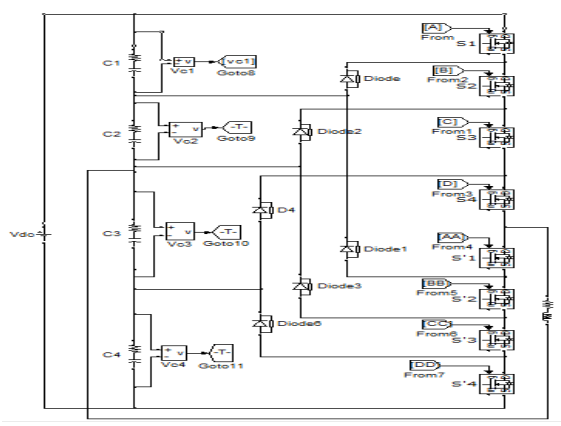

Figure 1: five -level diode clamped inverter

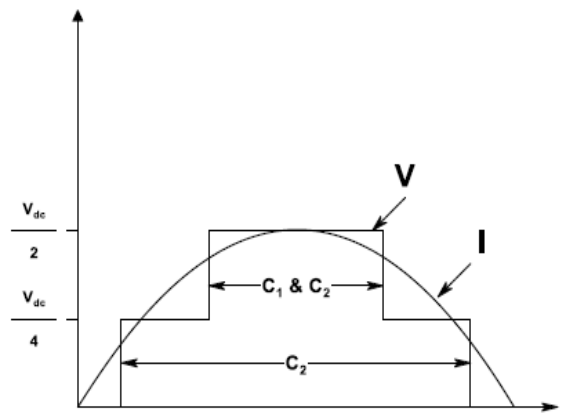

Figure 2 :DC capacitor voltage unbalancing [1]

\subsection{Switching technique for multilevel inverter}

The switching technique employed here is phase disposition pulse width modulation scheme.

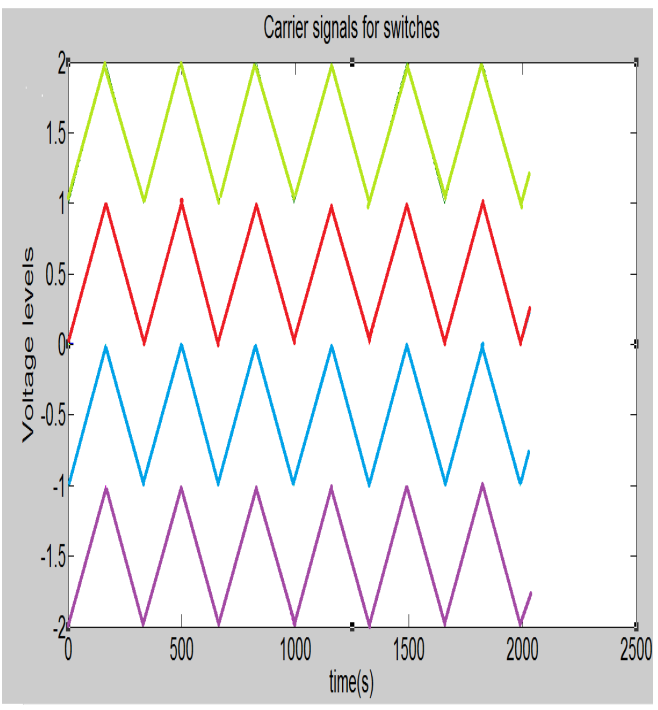

Figure 3:SPWM switching signal

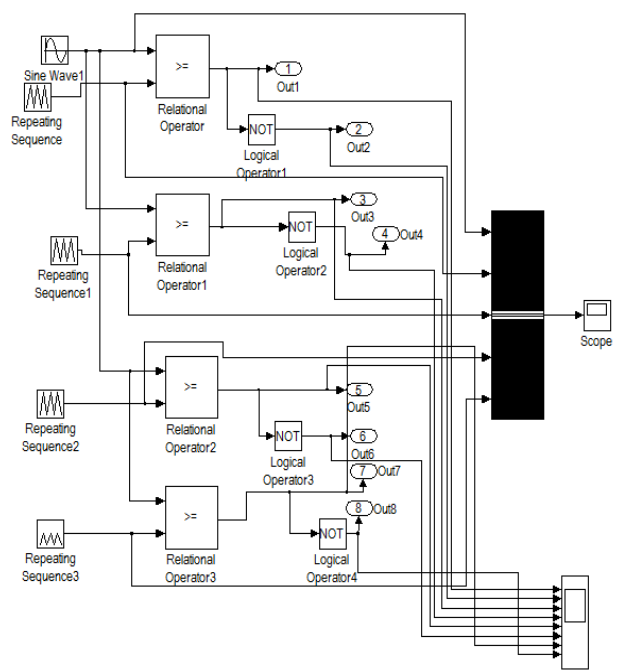

Figure 4:switching control operation

Here as shown in fig.4 the four triangular carrier signal waves are used which are all having same frequency, same amplitude and are equally displaced from each other but the only difference is change in the dc offset so as to occupy different levels. This carrier waves are then compared with the sinusoidal reference signals and based on this the switches are turned on accordingly. The other two switching scheme available are phase-opposition disposition pulse width modulation where are the two carrier wanes are in phase with each other and the other two are in opposition to first two carrier and alternate phase-opposition disposition pulse width modulation where carrier waves are alternately phase opposed to each other [1]. It is found that employing pdpwm technique reduces the THD level to $20.73 \%$ for modulation index of 0.9 .For reducing the THD LC filter is being employed. 


\section{LC filter design}

It has been determined that the output voltage and current of inverter consist of large harmonic components as a result of switching signals. By choosing a higher frequency for the inverter the higher harmonics could be filtered out more easily.LC filter is widely used for filtering out the harmonics in inverter output [5].

The value of inductor $\mathrm{L}$ is being calculated using the following equation:

$$
\mathrm{L}=\mathrm{V}_{\mathrm{p}} / 2 * 2.44 * \mathrm{f}_{\mathrm{s}} * \mathrm{i}_{\text {ripple,peak }}
$$

Where $f_{s}$ is the inverter switching freqency and $V_{p}$ is the rms phase voltage. The value of the inductor is selected such that the value of inductor current ripple is limited to $15 \%$.

Similarily the value of $\mathrm{C}$ is being calculated using the following equation:

$$
\mathrm{C}=1 /\left(2 * \pi * \mathrm{f}_{0}\right)^{2} * \mathrm{~L}
$$

Where $f_{o}$ is the cutoff frequency,this value of cutoff frequency is $1 / 6^{\text {th }}$ of the fundamental freqency.This LC filter is thus employed at the load side so that a filtered output provides a smooth operation for the load.By using LC filter the level of THD is reduced to $0.47 \%$.

\section{Two-level boost converter}

Here in this paper the five-level diode clamped inverter inner capacitor voltage balancing is being managed by a two-level boost converter as shown in Fig5. The TLBC has advantages in reducing recovery losses of the diodes and switching losses. The conventional boost converter consists of two separate switching inductors which leads to the increase in cost of the circuit. With the introduction, of the modified boost converter in the form of two level boost-converter there is reduction in inductor ripple current because of which the size of inductor is reduced to half the size of rating requirement compared to conventional boost-converter [4].

\subsection{Inner capacitor voltage balancing}

The circuit for TLBC is as shown in Fig 5. The switching signal in switches $S_{1}$ and $S_{2}$ are turned on alternately here the switching signals do not overlap each other for some duration of time since they are turned alternately on and off [5]. The switching signal shown are for the duty ratio of 0.5 . This TLBC operates in four different modes.
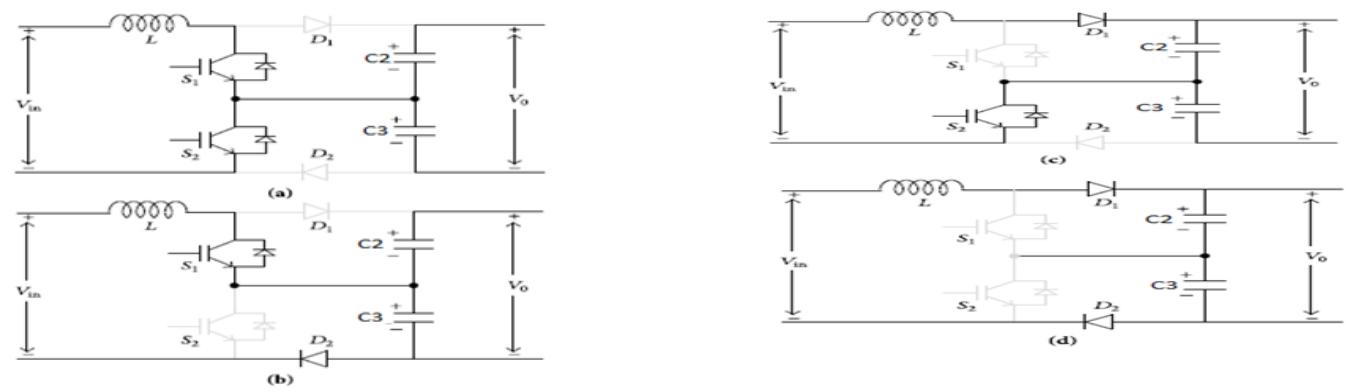

Figure 6: Modes of boost converter

In mode (a) both the switches $\mathrm{S}_{1}$ and $\mathrm{S}_{2}$ are on. Followed by alternate switching on and off of the switches in mode (b) and mode (c) respectively and switching of both the switches in mode 4 where the load is directly being supplied by the source. In mode (a) energy is being stored in the inductor as both $S_{1}$ and $S_{2}$ are in on condition. In mode (b) and (c) $C_{2}$ and $C_{3}$ are alternately charged to a higher level and in mode (d) load is directly supplied by the source. Capacitors $\mathrm{C}_{2}$ and $\mathrm{C}_{3}$ can be charged to the required voltage level by changing the duty ratio interval with the help of changing in the charging 
duration. TLBC could be operated in five different algorithms [5].In this paper,one of the algorithm where time switching of $S_{1}$ and $S_{2}$ overlap each other is used.

\section{Simulations and results}
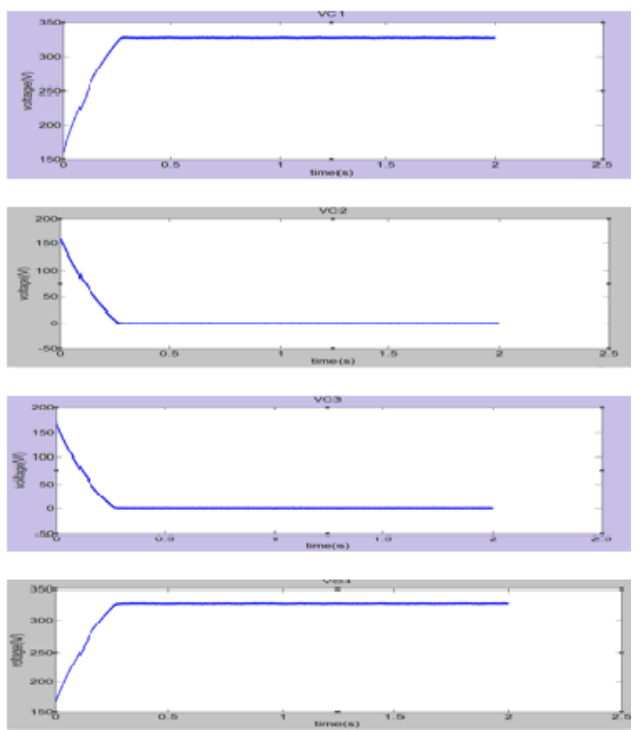

Figure 7: unbalancing in capacitor voltages

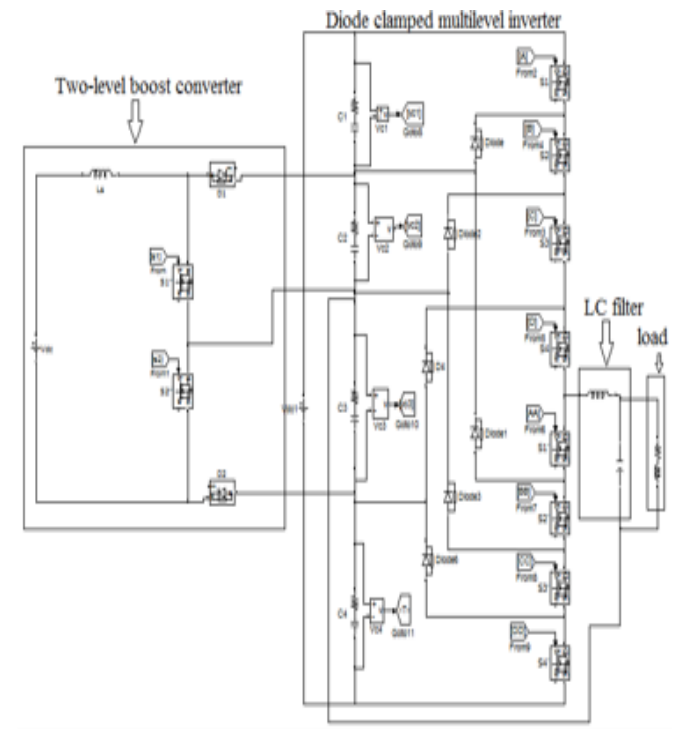

Figure8: boost converter with inverter

\begin{tabular}{ll}
\hline Parameters & Value \\
\hline DC source voltage for boost converter & $180 \mathrm{~V}$ \\
DC source voltage for inverter & $625 \mathrm{~V}$ \\
DC capacitor voltage & $2200 \mathrm{microfarad}$ \\
Carrier frequency in boost converter & $5 \mathrm{KHz}$ \\
Carrier frequency in inverter & $5.5 \mathrm{khz}$ \\
\hline
\end{tabular}

Table-1 parameters for simulation circuit

fg. 7 shows the unbalancing in the capacitor voltages which is being balanced by addition of boostconverter as shown in fig. 8. This circuit is being tested for different resistive values of $50 \mathrm{ohms}$ and $54 \mathrm{ohm}$ and inductive load of $\mathrm{L}=28.7 \mathrm{mH}$ and $32.7 \mathrm{mH}$. as shown in fig.9 

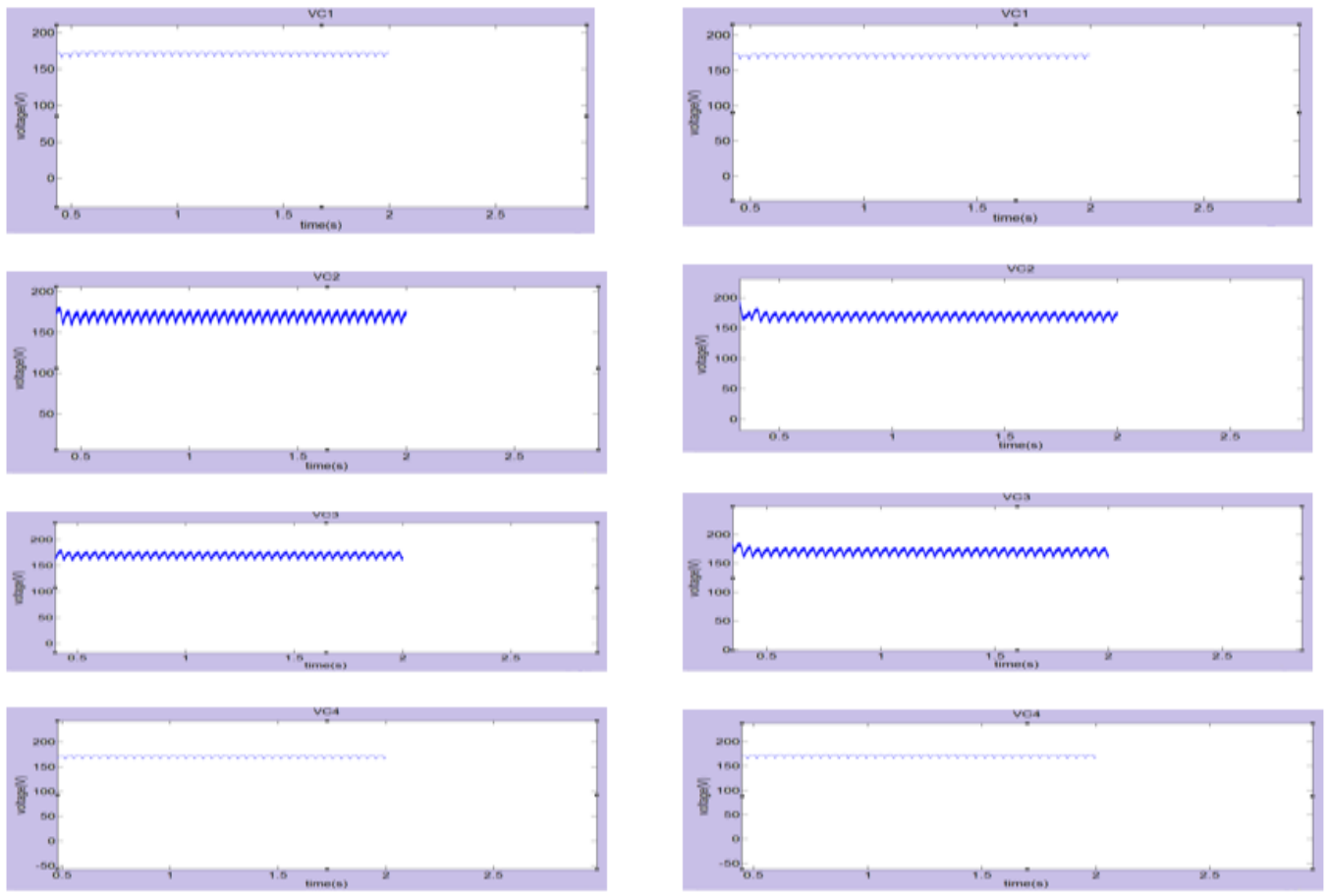

Figure9: Balancing after boost converter

\section{Conclusion}

The research conducted in this configuration works well for balancing of the capacitor voltages leading to the uniformity in the output voltage in terms of maintaining the required output voltage levels and increase in the life of dc link capacitor by appropriate usage of all the capacitors voltage levels. The circuitry could thus be employed for different loading conditions

\section{References}

1. M.H.Rashid(2006), Power Electronics Circuits,Devices and Applications, PEARSON.

2. A.A Boora,A.Nami,F.Zare,A.Ghosh and F. Blaabjerg (Oct 2010)"Voltage sharing converter to supply single phase assymetrical four level diode clamped multilevel inverter with high power factor loads", IEEE Trans. Power Electron, vol. 25, no. 10, (pp. 2507-2520).

3. V.I Meleshin,D.V.Zhiklenkov, and A.A.Ganshien(2012), "Efficient three level boost converter for various applications", in Proc.Power Electron.Motion Control Conf.

4. Ronalad Y. Barazarte,Guadalupe G.Gonzalex (Aug 14-16 2013),’Design Of a two-level boost converter",in EleventhLACCEIlatin american and carribean conference of engineering and technology.

5. Yew Weng Kean,Pang Siew Yong,Agileswari Ramaswamy and V.K Ramachandaramurthy(Nov 2015), "Comparision of effect of filter design on total harmonic distortation in three phase stand alone photovoltaic system", ARPN Journal Of Engineering and Applied Science, vol. 10, (no. 21). 